\title{
Diabetes in the Elderly Adults: Characteristics in Black African Diabetic Patients in Cotonou -Benin
}

\author{
François Djrolo*, Jules Gninkoun and Adebayo Alassani \\ Faculty of Health Sciences, Department of Internal Medicine - Endocrinology, Metabolism and Nutrition Unit, Cotonou, Bénin
}

\section{Article Info}

*Corresponding author:
François Djrolo
Faculty of Health Sciences
Department of Internal Medicine -
Endocrinology, Metabolism and Nutrition
Unit
Cotonou, Bénin
E-mail: fdjrolofss@yahoo.fr

Received: July 28, 2015

Accepted: August 14, 2015

Published: August 19, 2015

Citation: Djrolo F, Gninkoun J, Alassani A. Diabetes in the Elderly Adults: Characteristics in Black African Diabetic Patients in Cotonou - Benin. Madridge J Diabetes. 2015; 1(1): 1-4. doi: 10.18689/mjd-1000101

Copyright: @ 2015 The Author(s). This work is licensed under a Creative Commons Attribution 4.0 International License, which permits unrestricted use, distribution, and reproduction in any medium, provided the original work is properly cited.

Published by Madridge Publishers

\begin{abstract}
Background: According to literature data, 23\% of diabetic subjects are more than 65 years old and high prevalence of microvascular and macrovascular complications are responsible for a high rate of morbidity and mortality in elderly diabetic patients.

Objective: To evaluate the frequency of elderly diabetic patients and to identify factors associated with high morbidity and mortality rate.

Patients and Method: It is a cross- sectional study including diabetic patients hospitalized from 2010, January $1^{\text {st }}$ to 2012 , December $31^{\text {st }}$. Were considered elderly diabetic patients, patients who were 65 years or more old. Statistical analysis was performed using Chi [2] test and Student test. Difference was considered significant for $p<0.05$.
\end{abstract}

Results: A total of 478 patients were hospitalized during the study period and 135 were 65 years or older making a prevalence rate of elderly diabetic patients of $28.20 \%$. Mean age of elderly diabetic patients was $71.83 \pm 6.32$ years with extremes of 65 and 94 years. The main complications observed were significantly more frequent in elderly diabetic patients than in others: diabetic foot, $46.70 \%$ versus $17.0 \%\left(p<10^{-4}\right)$; poor control of diabetes, $28.10 \%$ versus $35.10 \%$ ( $p<0.07$ ); Hyperglycaemic hyperosmolar syndrome, $20.0 \%$ versus $10.0 \%$ $(p=0.002)$; Neuropathy, $54.90 \%$ versus $17.70 \%\left(p<10^{-4}\right)$; Leg arteriopathy, $48.90 \%$ versus $10.80 \%\left(p<10^{-4}\right)$ and diabetic nephropathy, $37.80 \%$ versus $3.0 \%\left(p<10^{-4}\right)$. The same figure was observed with high blood pressure, $87.89 \%$ versus $63.94 \%(p=0.03)$. The evolution during hospitalization was marked by a high mortality rate of $34.10 \%$. All chronic complications of diabetes (arteriopathy, retinopathy, nephropathy, neuropathy and diabetic foot) were significantly more frequent in elderly diabetic patients than in nonolder and were significantly associated with mortality with $p$ value $<10^{-4}$.

Conclusion: Elderly adult diabetes become more and more prevalent even in developing countries and is responsible for a high rate of morbidity and mortality. The main cause of hospitalization was diabetic foot. Education for diabetic foot prevention would allow to reduce hospitalization rate and mortality rate in elderly diabetic patients.

Keywords: Diabetes; Elderly subjects; Complications; Mortality.

\section{Introduction}

All recent estimation studies on diabetes mellitus report a worrying increase in the prevalence of the disease worldwide and particularly in the developing countries [1,2]. In subsaharan Africa, the number of subjects with diabetes was estimated to 19.8 million in 2013 realizing a prevalence rate of $4.8 \%$ and was thought to grow to 41.5 million in 2035 with a prevalence rate of $5.3 \%$ [3]. In Benin, the same trend was observed in the evolution of the disease with a prevalence rate of $1.1 \%$ in 2001 , growing to $2.6 \%$ in $2008[4,5]$. This increase of the prevalence of diabetes mellitus is often related to life style modifications with development and urbanization but can also be explained by the improvement of 
life conditions and especially in developing countries, by the reduction of transmissible and nutritional diseases and consequently the increase of life expectancy. All epidemiological studies of diabetes have underlined the increase of the prevalence with age $[4,6,7]$. People living older, diabetes in the older age is becoming a public health concern problem even in developing countries. A high prevalence of microvascular and macrovascular complications was reported to be responsible for a high rate of hospitalization and death in elderly diabetic patients [8]. In subsaharan Africa very few studies have been devoted to diabetes in the elderly adults.

\section{Objective}

The objective of the present study was to determine the frequency of elderly subjects among diabetic patients hospitalized in the endocrine and metabolism unit of the teaching hospital in Cotonou and to identify factors associated with morbidity and mortality in these patients.

\section{Patients and Method}

The study was a retrospective and transversal study interesting diabetic patients of both sexes hospitalized in the unit from 2010 January the $1^{\text {st }}$ to 2012 December the $31^{\text {st }}$. Patients of 65 years or more were defined as elderly adult patients [9]. Diabetes mellitus was defined according to the American Diabetes Association criteria [10]. The medical report of every patient was screened. Parameters investigated were age of patients, the control of the diabetes, the presence of long term complications and the final evolution of the patient. About long term complications, ischemic heart disease was defined as the presence of characteristic electrocardiographic signs of ischemia. Leg arteriopathy was defined with the disappearance of distal pulses and/or the objectivation of characteristic lesions at arterial Doppler ultrasonographic examination. Systolic index pressure were not measured. Retinopathy was defined with the presence of characteristic lesions at eye fundoscopy. Diabetic nephropathy was defined with the presence of significant microalbuminuria ( $\geq 30 \mathrm{mg} / 24 \mathrm{~h}$ ) or proteinuria coexisting with retinopathy in the absence of other cause of proteinuria.

The control of the diabetes was evaluated with glycated haemoglobin level and was considered optimal with glycated haemoglobin level less than $7 \%$. Glycated haemoglobin level between $7 \%$ and $8 \%$ defined a poor control of diabetes and glycated haemoglobin level higher than $8 \%$ defined a bad control. Chi [2] test was used for statistical analysis and difference observed was considered significant with $p<0.05$.

\section{Results}

\section{Characteristics of Patients}

During the study period, a total of 478 patients were hospitalized in the service. Of them, 135 were 65 years or older representing a frequency of $28.20 \%$. The mean age of elderly diabetic patients was $71.83 \% \pm 83$ years. Concerning gender, Women represented $52.60 \%$ of patients. As shown in figure 1, frequency of elderly diabetic patients grown with years from $23.10 \%$ in 2010 to $40.70 \%$ in 2012 .

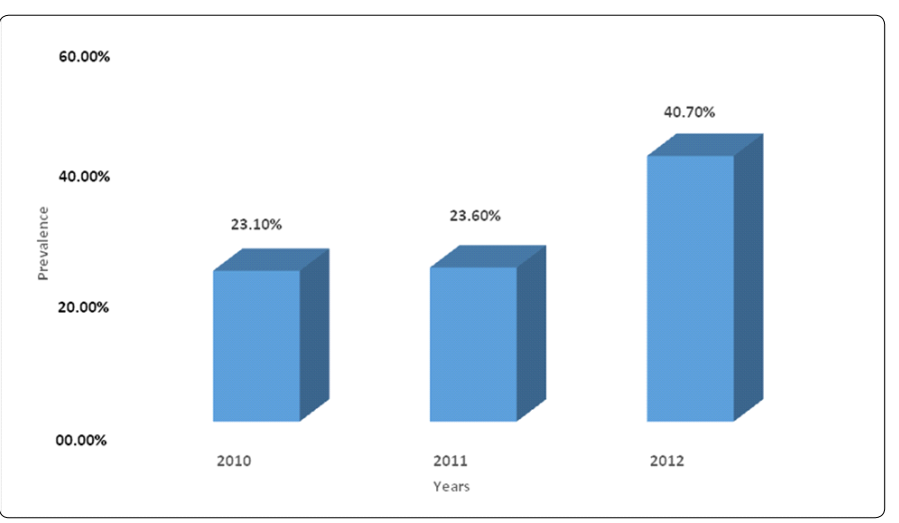

Figure 1: Variation of the frequency of elderly diabetic patients with years.

\section{Causes of Hospitalization}

Causes of hospitalization were recapitulated in table 1 and we can see that the more frequent causes in the elderly patients were foot ulcer and hyperglycemic hyperosmolar syndrome.

\begin{tabular}{|c|c|c|c|c|c|}
\hline \multirow{2}{*}{ Causes of Hospitalization } & \multicolumn{2}{|c|}{ Elderly Patients } & \multicolumn{2}{c|}{ Non Elderly Patients } & \multirow{2}{*}{$p$} \\
\cline { 2 - 5 } & Number & Percentage & Number & Percentage & \\
\hline Poor control of diabetes & 38 & $28.10 \%$ & 120 & $35.10 \%$ & 0.07 \\
\hline $\begin{array}{c}\text { Hyperglycemic } \\
\text { Hyperosmolar syndrome }\end{array}$ & 27 & $20.0 \%$ & 34 & $10.0 \%$ & 0.002 \\
\hline Keto-acidosis & 7 & $5.20 \%$ & 130 & $37.90 \%$ & $<10^{-10}$ \\
\hline Diabetic Foot & 63 & $46.70 \%$ & 58 & $17.0 \%$ & $<10^{-9}$ \\
\hline Total & 135 & $100 \%$ & 342 & $100 \%$ & \\
\hline
\end{tabular}

Table 1: Causes of hospitalization in elder and non-elder diabetic patients.

As shown in table 2, all degenerative complications were significantly higher in the elderly diabetic patients than the other. The more frequent complications were successively retinopathy, neuropathy and ischemic heart disease.

\begin{tabular}{|c|c|c|c|c|c|}
\hline \multirow{2}{*}{ Complications } & \multicolumn{2}{|c|}{ Elderly Patients } & \multicolumn{2}{|c|}{ Non Elderly Patients } & \multirow{2}{*}{$p$} \\
\hline & Number & Percentage & Number & Percentage & \\
\hline Stroke & 8 & $6.0 \%$ & 1 & $0.30 \%$ & 0.002 \\
\hline Ischemic heart disease & 64 & $48.10 \%$ & 37 & $10.80 \%$ & $<10^{-4}$ \\
\hline Leg arteriopathy & 65 & $48.90 \%$ & 37 & $10.80 \%$ & $<10^{-4}$ \\
\hline Retinopathy & 95 & $71.40 \%$ & 75 & $21.90 \%$ & $<10^{-4}$ \\
\hline Nephropathy & 51 & $37.80 \%$ & 10 & $3.0 \%$ & $<10^{-4}$ \\
\hline Neuropathy & 73 & $54.90 \%$ & 60 & $17.70 \%$ & $<10^{-4}$ \\
\hline
\end{tabular}

Table 2: Complications in elderly and non-elderly patients.

\section{Diabetes Control and Evolution}

Looking at glycated haemoglobin level, only $9.30 \%$ of patients shared an optimal control of the diabetes at admission. A poor control was observed in $11.30 \%$ of patients and in the majority $(79.40 \%)$, diabetes control was bad. In the elderly diabetic patients, $66.40 \%$ of patients were treated with insulin and oral hypoglycemic agents were used in $33.60 \%$ of them when $43.70 \%$ of the other patients were treated with insulin and $54.70 \%$ with oral hypoglycemic agents. The difference was significant with $p<10^{-4}$. Regarding the evolution 
during the hospitalization, $34.10 \%$ of death were observed in elderly diabetic patients versus $5.80 \%$ in the others $\left(p<10^{-4}\right)$. The main conditions associated with elevated mortality in elderly diabetic patients were the presence of degenerative complications (Table 3).

\begin{tabular}{|c|c|c|c|}
\hline Factors & Dead Patients & Alive Patients & P \\
\hline Diabetic foot & $45(68.20)$ & $70(17.10)$ & $<10^{-4}$ \\
\hline Pulsed pressure $(\mathrm{mm} / \mathrm{Hg})$ & $57.08 \pm 10.78$ & $54.65 \pm 11.63$ & 0.05 \\
\hline Leg arteriopathy & $37(56.10)$ & $65(15.90)$ & $<10^{-4}$ \\
\hline Retinopathy & $44(66.70)$ & $126(30.80)$ & $<10^{-4}$ \\
\hline Neuropathy & $36(55.40)$ & $97(23.80)$ & $<10^{-4}$ \\
\hline Nephropathy & $22(33.80)$ & $39(9.70)$ & $<10^{-4}$ \\
\hline
\end{tabular}

( ): Percentage

Table 3: Factors associated with death in elderly diabetic patients.

\section{Discussion}

In the present study, the frequency of $28.20 \%$ found for elderly subjects diabetes was not far from the number of $23 \%$ reported in USA in 2002 [11]. On the other hand, Charles, et al. [12] have reported a higher prevalence rate of $44.08 \%$ in Senegal in 1987. This higher prevalence can be explained by the definition used for elder subject, which definition was based on the age of 60 years when our cut off was 65 years. The growing population of elderly diabetic patients in black Africa can be explained by many factors among witch the increase of the prevalence of diabetes, the better treatment of the disease resulting in longer life expectancy, the large campaigns of sensitization and screening.

The most frequent cause of hospitalization of elderly diabetic patients in our study was foot wound. This result is concordant with the report of Mitty, et al. [13] who reported in 2009 that the main cause of hospitalization of elderly diabetic patients in USA was foot lesions in $75 \%$ of cases. This high rate of foot wound can be explained by the high rate of arteriopathy and neuropathy, the main etiopathogenic factors of diabetic foot $[14,15]$. Not surprisingly frequency of ketoacidosis was significantly lower in elder patients because type 1 diabetes which is the ketone prone diabetes is well known as a pathology of younger people.

Microvascular complications were dominated by retinopathy and neuropathy with a respective rate of $71.40 \%$ and $54.90 \%$. Lower rate of retinopathy (38\%) was reported by Otiniano, et al. in a multicentric study [11] and in literature data, prevalence rate of retinopathy was situated about $34 \%$. $[16,17]$ The high rate observed in our study is probably related to the fact that the study was focused on hospitalized patients so patients with complications and in this condition, prevalence rate can be overestimated.

Regarding leg arteriopathy, our finding was closed to the rate of $42 \%$ reported by Mendelson [18] but a lower rate (32.4\%) has been reported in the elderly diabetic patients by Guerchet in Brazzaville in 2012 [19]. In our study, the evolution of the disease in hospitalized elderly diabetic patients resulted in a high rate of mortality of $34.10 \%$ when Bertoni in a two years running study has reported a lower mortality rate of
$14.8 \%$ in USA [20]. However, like us, Bertoni in his study underlined diabetic foot as the main cause of morbidity and mortality. The high mortality rate in our study can be explained by many factors among which can be listed delay in consultation, the poor level of the therapeutic set and the absence of health care insurance.

\section{Conclusion}

Diabetes in elderly adult subjects becomes more and more prevalent inducing high rate of morbidity and mortality. Diabetic foot with its vascular component appeared as the main cause of hospitalization in elderly diabetic patients. In our context of practice with poor therapeutic set and absence of revascularization possibility, education for diabetic foot prevention would be the best way to reduce hospitalization and mortality rate in elderly diabetic patients.

Conflicts of Interest: The authors declare no conflicts of interest.

Consent: Patient has provided written consent for publication of this study.

\section{References}

1. Shaw J, Secree R, Zimmet P. Global estimates of the prevalence of diabetes for 2010 and 2030. Diabetes Res Clin Pract. 2010; 87: 4-14. doi: 10.1016/j.diabres.2009.10.007

2. Whiting D, Guariguata I, Weil C, Shaw J. IDF diabetes atlas: global estimates of the prevalence of diabetes for 2011 and 2030. Diabetes Res Clin Pract. 2011; 94: 311-321. doi: 10.1016/j.diabres.2011.10.029

3. International Diabetes Federation. Diabetes Atlas, 6th edition 2013.

4. Djrolo F, Amoussou-Guenou KD, Zannou D, Houinato D, Ahouandogbo F. Prévalence du diabète sucré au Bénin. Louvain Médical. 2003; 122: 256-260.

5. Djrolo F, Gbary A, Houinato D, Fambo D, Djigbénoudé O. Prevalence of diabetes mellitus and associated factors in the general population in Benin. IDF 2011 world diabetes congress abstracts book. 570: P1774.

6. Balde N-M, Diallo I, Baldé $M-D$, et al. Diabetes and impaired fasting glucose in rural and urban population in Futa Djallon (Guinea): Prevalence and associated risk factors. Diabetes Metab. 2007; 33: 114120. doi : 10.1016/j.diabet.2006.10.001

7. Simon D. Définition, dépistage et épidémiologie du diabète de type 2 . Médecine des Maladies Métaboliques. 2008; 2(S1): S5-S9.

8. Laura AM. Diabetes control in older people: Treat the patient, not the $\mathrm{HbA}_{1}$ c. BMJ. 2013; 346: 1-2. doi: 10.1136/bmj.f2625

9. World Health Organization. Definition of older or elderly person. Website: http://www.who.int/healthinfo/survey/ageingdefnolder/en/ 2013; Accessed June 20, 2013.

10. Standards of Medical care in diabetes - 2013. Diabetes Care. 2013; 36: S11-S66. doi: 10.2337/dc13-S011

11. Otiniano ME, Black SA, Ray La, Du X, Markides KS. Correlates of diabetic complications in Mexican- American elders. Ethn Dis. 2002; 12: 252-258.

12. Charles $D$, Gueye $P M$, Wade $B$. Le diabète du sujet âgé : à propos de 52 observations consécutives. Médecine d'Afrique Noire. 1997; 44: 18-23.

13. Mitty E. Nursing care of the aging foot. Geriatr Nurs. 2009; 30: 350-354 doi: 10.1016/j.gerinurse.2009.08.004

14. Nil T, Muammer B, Teoman Y, Ozalp K. Prevalence of peripheral arterial disease and related risk factors in Turkish elders. BMC Family Practice. 2011; 12: 1-6. doi: 10.1186/1471-2296-12-96 
15. Naliboff $\mathrm{BD}$, Rosenthal M. Effects of age on complications in adult onset diabetes. J Am Geriatr Soc. 1989; 37: 838-842.

16. Joanne WY, Sophie IR, Ryo K, et al. Global prevalence and major risk factors of diabetic retinopathy. Diabetes care. 2012; 35: 556-564. doi: $10.2337 / \mathrm{dc} 11-1909$

17. Engelgau MM, Saaddine JB, Boyle JP, Benjamin SM, Gregg EW. The evolving diabetes burden in the United States. Ann Intern Med. 2004; 140: 945-950. doi: 10.7326/0003-4819-140-11-200406010-00035

18. Mendelson G, Aronow WS, Ahn C. Prevalence of coronary artery disease, atheromatic brain infarction and peripheral arterial disease: associated risk factors in older Hispanics in an academic hospital-based geriatric practice. J Am Geriatr Soc. 1998. 46: 481-483.
19. Guerchet $M$, Aboyans $V$, Mbelesso $P$, et al. Epidemiology of peripheral artery disease in elder general population of two cities of Central Africa: Bangui and Brazzaville. Eur J Vasc Endovasc Surg. 2012; 44: 164-169. doi: 10.1016/j.ejvs.2012.05.019

20. Bertoni AG, Krop JS, Anderson GF, Brancati FL. Diabetes-related morbidity and mortality in national sample of US elders. Diabetes care. 2002; 25: 471-475. doi: 10.2337/diacare.25.3.471 